\title{
Assessment of the Quality and Reliability of Information on Nutrition for Patients with Diabetes on YouTube
}

\author{
Nazlı Batar ${ }^{1 *}$, Gizem Aşkın², Elif Beyza İpek³ ${ }^{3}$ Sezen Sevdin ${ }^{4}$, Rümeysa Özçalkap ${ }^{5}$
}

${ }^{1}$ Istanbul Kültür University, Health Sciences Faculty, Department of Nutrition and Dietetics, Istanbul, Turkey, (ORCiD: 0000-0001-9527-5709), n.batar@iku.edu.tr ${ }^{2}$ Istanbul Kültür University, Health Sciences Faculty, Department of Nutrition and Dietetics, Istanbul, Turkey, (ORCID: 0000-0002-6209-1361), gizemaskin@hotmail.com

${ }^{3}$ Istanbul Kültür University, Health Sciences Faculty, Department of Nutrition and Dietetics, Istanbul, Turkey, (ORCID: 0000-0002-1291-5844), ipeekli1@gmail.com ${ }^{4}$ Fenerbahce University, Health Sciences Faculty, Department of Nutrition and Dietetics, Istanbul, Turkey, (ORCID: 0000-0002-5961-8054), sezen.sevdin@,fbu.edu.tr

${ }^{5}$ Istanbul Kültür University, Health Sciences Faculty, Department of Nutrition and Dietetics, Istanbul, Turkey, (ORCID: 0000-0002-8006-0411), r.ozcalkap@iku.edu.tr

(İlk Geliş Tarihi 8 Eylül 2021 ve Kabul Tarihi 16 Kasım 2021)

(DOI: $10.31590 /$ ejosat.992770)

ATIF/REFERENCE: Batar, N., Aşkın, G., İpek, EB., Sevdin, S., \& Özçalkap, R. (2021). Assessment of the Quality and Reliability of Information on Nutrition for Patients with Diabetes on YouTube. European Journal of Science and Technology, (31), $268-274$.

\begin{abstract}
Background/Objectives: The purpose of this study was to evaluate the accuracy, and the quality of the information of the videos about diabetes and nutrition on YouTube. Subjects/Methods: Using the keywords "diabetic diet" and "nutrition of diabetic patient", a search was conducted on YouTube, and the first 100 videos for each keyword, 200 videos in total were analyzed. The popularity of the videos was calculated using the video power index (VPI) and view rates. Among these 200 videos, 32 were non-English videos, 36 were nonnutritional videos, and 38 were duplicate videos. The quality and the accuracy of the information was evaluated using the DISCERN score, the Journal of the American Medical Association (JAMA) score, the Global Quality Score (GQS), the usefulness score, and a novel diabetic diet score (DDS). SPSS 20 was used for statistical analysis. Results: Physician, dietitian, commercial, and patient-sourced videos differed significantly in DISCERN, GQS, and usefulness scores $(\mathrm{p}<0.05)$. In the DISCERN, GQS, and usefulness scores, physician sourced videos had statistically higher scores than commercial-sourced videos (.0125). A significant and positive correlation was found between view ratio and video power index. Besides, there was a statistically significant and positive correlation between the number of views and DISCERN, JAMA, GQS, usefulness score and DDS, while a positive correlation was found between number of likes and video strength indexes $(\mathrm{p}<0.001)$. Conclusions: It has been observed that videos on nutrition for diabetic patients on YouTube are of low quality in terms of quality and reliability.
\end{abstract}

Keywords: YouTube, Diabetic Diet, Nutrition of Diabetic Patient, Patient Education, Information, Quality Video

\section{Diyabetli Hastalara Yönelik YouTube'da Yayınlanan Beslenme Bilgi Paylaşımlarının Kalite ve Güvenirliğinin İncelenmesi}

Öz

Arka Plan/Amaç: $\mathrm{Bu}$ çalışmanın amacı, YouTube'daki diyabet ve beslenme ile ilgili videoların doğruluğunu ve kalitesini değerlendirmektir. Denekler/Yöntemler: "Diyabetik diyet" ve "şeker hastasının beslenmesi" anahtar kelimeleri kullanılarak YouTube'da arama yapılmış ve her bir anahtar kelime için ilk 100 video olmak üzere toplam 200 video analiz edilmiştir. Videoların popülaritesi, video güç indeksi (VPI) ve görüntüleme oranları kullanılarak hesaplandı. Bu 200 videonun 32'si İngilizce olmayan videolar, 36'sı beslenme dışı videolar ve 38'i yinelenen videolardı. Bilgilerin kalitesi ve doğruluğu DISCERN puanı, Journal of the American Medical Association (JAMA) puanı, Global Kalite Puanı (GQS), kullanışlılık puanı ve yeni bir diyabetik diyet puanı (DDS) kullanılarak değerlendirildi. İstatistiksel analiz için SPSS 20 kullanıldı. Sonuçlar: Hekim, diyetisyen, ticari ve hasta kaynaklı videolar DISCERN, GQS ve kullanışlılık puanlarında anlamlı farklılık gösterdi $(\mathrm{p}<0.05)$. DISCERN, GQS ve kullanışlılık puanlarında, hekim kaynaklı videolar, ticari kaynaklı videolardan istatistiksel olarak daha yüksek puanlara sahipti (.0125). Görüntüleme oranı ile video güç indeksi arasında anlamlı ve pozitif bir ilişki bulundu. Ayrıca izlenme sayısı ile DISCERN, JAMA, GQS, kullanışlılık puanı ve DDS arasında istatistiksel olarak anlamlı ve pozitif bir ilişki bulunurken, beğeni sayısı ile video güç indeksleri arasında pozitif bir ilişki bulundu $(p<0,001)$. Sonuç: YouTube'da diyabet hastaları için beslenme ile ilgili videoların kalite ve güvenilirlik açısından düşük kalitede olduğu görülmüştür.

Anahtar Kelimeler: YouTube, Diyabetik Diyet, Diyabetik Hastanın Beslenmesi, Hasta Eğitimi, Bilgilendirme, Kaliteli Video

* Corresponding Author: n.batar@iku.edu.tr 


\section{Introduction}

The internet, used for information transfer, entertainment, shopping, etc., is accepted as a tool that can quickly enable people to communicate with each other (Gimenez-Perez et al. 2020). Currently, the internet is used in nearly every home and area of the world (Fox and Duggan, 2012). In addition, health information is one of the most sought-after topics on the internet, and the use of social media is an increasingly popular platform for delivering health information to the public (Fox and Duggan, 2012). Many studies have been conducted on internet usage around the world. As a result of these studies, it has been determined that the internet has many disadvantages as well as numerous advantages (Fox and Duggan, 2012; Ferhatoglu et al. 2019).

YouTube $^{\mathrm{TM}}$ (https://www.youtube.com) is one of the most frequently used online platforms worldwide. Almost every minute, a new video is uploaded to YouTube that can exceed 2 billion views per day (Smith et al. 2019). According to a study by the Health Information National Trends Survey (HINTS), it has been determined that compared to the past, individuals more frequently prefer the internet now to access information about their health status (Madathil et al. 2015). According to recent surveys, it has been determined that 8 out of every 10 internet users access health information from online platforms (Atkinson 2009; Rutten et al. 2006). Information sharing has both positive and negative consequences, due to ever-increasing technology opportunities. Although YouTube, which is increasingly frequently used by healthcare professionals and students, is useful as a visual resource, it can also facilitate inaccurate and insufficient information transfer (Erdem and Sisik 2018; Erdem and Karaca 2018; Celik et al. 2020). Misleading videos may cause patients to make incorrect decisions and have negative effects on the patient-physician relationship (Pant et al. 2015).

Diabetes, which is accepted as one of the most important health problems in the world today, is increasing rapidly in Turkey as in the rest of the world (Wild et al. 2004). Due to this increase, patients and physicians have used sources shared on many platforms, including YouTube, to access information faster (Coşansu 2015). These platforms provide everyone, including patients with diabetes (and many other diseases), the opportunity to access information more easily. In this study, we aimed to evaluate the accuracy, and the quality of the information of the videos about diabetes and nutrition on YouTube (Abedin et al. 2015).

Diabetes is an important health problem. Medical nutrition therapy is an important component in the management of diabetes. Dietitians who are experts in the field of diabetes and nutrition play a key role in the control of diabetes. The duty of a diabetes dietician is to determine and evaluate the individual's food consumption, food portion, nutritional behaviors and to prepare the appropriate nutrition program (Özer 2019).

\section{Material and Methods}

A YouTube search was carried out on October 23, 2020, using the keywords "diabetic diet" and "nutrition of diabetic patient." Since the aim was to evaluate the diet-related videos, the two keywords of the article searched in Youtube were chosen by using the MeSH tool. All videos were ranked by YouTube's relevance criteria. Assuming that users would not look beyond the fifth page of the search results, the first 100 videos were used for each keyword (Erdem and Sisik 2018; Ferhatoglu et al. 2019; Celik et al. 2020). Among these 200 videos, 32 were non-English videos, 36 were nonnutritional videos, and 38 were duplicate videos. The analysis of the videos was performed by three researchers (NB, $\mathrm{GA}$, and EBI). The researchers watched and evaluated each video independently. The quality of the information of the videos was evaluated using the DISCERN score, the Journal of the American Medical Association (JAMA) score, the Global Quality Score (GQS), the usefulness score, and the diabetic diet score (DDS).

DISCERN is a questionnaire with 3 parts and 16 questions in total. A higher questionnaire score represents better video quality (Charnock et al. 1999). In the questionnaire, the first 8 questions are about reliability and the next seven are about treatment. The final question of the questionnaire is a general evaluation question. In the DISCERN scoring system, 63-75 points represent excellent quality, 51-62 points represent good quality, 39-50 points represent average quality, 27-38 points represent low quality, and 16-26 points represent very low quality.

In the JAMA scoring system, the quality of the videos is evaluated according to 4 criteria (authorship, citation, explanation, and currency). In the JAMA evaluation, 1 point shows insufficient information, 2-3 points show partially sufficient information, and 4 points show completely sufficient information (Silberg et al. 1997).

The GQS is a questionnaire prepared by Bernard et al. and makes educational evaluations of a video. The GQS consists of 5 points: 1 point indicates low quality, 2 points indicates low but limited information quality, 3 points indicates optimum quality, 4 points indicates good quality, and 5 points indicates excellent quality (Bernard et al. 2007). The quality of the videos was assessed using the Global Quality Scale (GQS) which is a 5-point scale of 1-5 points and has been used for quality assessments in similar studies (Tolu et al. 2018; Bernard 2007). Video flow, usefulness, and quality can be evaluated using the GQS, with scores applied of 4-5 points indicating high quality, 3 points indicating moderate quality, and 1-2 points indicating low quality. The following scoring system was used in this study: 1 point: The video is of poor quality, poor flow, lacking most information, and therefore not useful for patients. 2 points: The video is generally of poor quality, and although some information is given, it is of limited use for patients. 3 points: The video is of moderate quality, and some important information is sufficiently discussed. In these videos, accurate and incorrect information are presented in a balanced manner. However, high-quality information is provided together with misleading information. 4 points: The video is of good quality and good flow. The video is useful for patients, covering the most relevant information and presenting accurate information to a large extent, but it may include minor deficiencies. 5 points: The video is of excellent quality and excellent flow and is very useful for patients. These videos include completely accurate information (Bernard 2007).

In the usefulness score created by Lee et al. videos are scored according to their information content as follows: 7-10 points, very useful; 3-7 points, helpful; and 1-2 points, useless (Lee et al. 2014). In this survey, 5 criteria were used according to the content of the videos: symptoms of the disease, diabetes treatment, nutrition, lifestyle, and complications of the disease. The best quality is indicated by 3 points for each criterion.

There is no specific measure available for the evaluation of diabetic nutritional information. For this reason, a YouTube-based 
diabetic diet score (DDS) system was designed. This score was developed by the researchers, informed by the American Diabetes Association (ADA) guidelines and Diabetes Canada Clinical Practice Guidelines (Han et al. 2020; Nutrition Therapy 2018).
Considering the diabetes guidelines, researchers determined 10 criteria that should be addressed in diabetic diet. A maximum of 10 points was awarded by giving 1 point to each of 10 criteria.

Table 1. Diabetic Diet Score (DDS)

\begin{tabular}{ll}
\hline Criteria & Points \\
\hline Carbohydrate type and its effect on blood & Max 1 point \\
Simple sugar consumption & Max 1 point \\
Water consumption & Max 1 point \\
Consumption of carbonated beverages and alcohol & Max 1 point \\
Frequency of main meals and snacks & Max 1 point \\
Proper food selections at meals & Max 1 point \\
Balanced diet & Max 1 point \\
Dietary fiber consumption & Max 1 point \\
regular follow-up & Max 1 point \\
Physical activity & Max 1 point \\
\hline
\end{tabular}

Considering the diabetes guidelines, researchers determined 10 criteria that should be addressed in diabetic diet. A maximum of 10 points was awarded by giving 1 point to each of 10 criteria. The videos were grouped as excellent (7-10 points), average (4-6), and poor (1-3).

The videos were categorized based on their source(s): dietitian, physician, patient, or commercial. The video power index (VPI) and view rate were used to determine the popularity of a video. The VPI was calculated using the equation [like ratio $\times$ view ratio/100], as described by Erdem et al. the like ratio was calculated using the equation (like $\times 100 /[$ like + dislike $]$ ), and the view ratio was calculated using the equation [number of views/time since upload] (Erdem and Karaca 2018; Celik et al. 2020).

The quality and the accuracy of the information was evaluated using DISCERN, JAMA, GQS, usefulness score and DDS.

Videos which are publicly available on YouTube were assessed, and no human participants/animals were included. Therefore, Ethics Committee approval was not required for this study. Similar studies have also followed the same path (Bernard 2007; Nason et al. 2015; Esen et al. 2019). Since any patient and patient-related material is not used in this study, an IRB is not required. Also, an IRB was not required in previous studies on this subject (Erdem and Sisik 2018; Ferhatoglu et al. 2019; Celik et al. 2020).

\section{Statistical Analysis}

SPSS 20 (SPSS Inc., Chicago, IL, USA) was used for statistical analysis. The frequency, percentage, minimummaximum values, mean, median, and standard deviation were used to describe DISCERN, GQS, JAMA, Usefulness, DDS, Time since upload (days), Run time (min), Views, Likes, Dislikes, Comments, View ratio, Like ratio, Video power index. The Shapiro-Wilk test was used to test the normal distribution suitability of all the data and within groups. It was observed that the data did not have a normal distribution within the groups or individually. For this reason, nonparametric statistical analysis was performed in the data analysis. The relationships between View ratio, Duration, Likes, VPI, DISCERN, JAMA, GQS, Usefulness and DDS were determined by the Spearman correlation, and comparisons between the DISCERN, JAMA, GQS, Usefulness, DDS, Video power index, View ratio scores regarding the video sources were performed using the Kruskal-
Wallis test. In case of a significant difference between groups, the Mann-Whitney U test was applied. The significance level was set at 0.05 for difference analysis and 0.01 and 0.05 for correlation analysis. Before group comparison, since there were four groups in the study, Bonferroni Correction was done. The significance level was accepted as $.05 / 4=.0125$ for group comprasions in the Mann-Whitney U test.

Since there are more than 2 raters, the Fleiss Kappa Coefficient was used to test inter-rater agreement. A coefficient of $<0$ means poor agreement, $0.0-0.20$ means slight agreement, 0.21 0.40 means fair agreement, 0.41-0.60 means moderate agreement, 0.61-0.80 means substantial agreement, and 0.81-1.0 means almost perfect agreement (Landis, Koch, 1977). Fleiss Kappa Coefficient was calculated in Microsoft Excel program (Landis \& Koch, 1977).

\section{Results and Discussion}

Ninety-four videos were evaluated within the scope of this study. Inter-rater agreement was evaluated with the Fleiss Kappa Coefficient. The coefficients for DISCERN, GQS, JAMA, USEFULNESS and DIABETIC SCORE were .996, .961, .992, 1.000 and 1.000 , respectively. It appears that there is an almost perfect agreement for all variables.

The descriptive statistics are given in Table 2. According to the DISCERN score, $5.3 \%$ of the videos were excellent, $11.7 \%$ were good, $17.0 \%$ were of medium quality, $36.2 \%$ were poor, and $29.8 \%$ were very poor. When the GQS was used, it was determined that $7.4 \%$ were excellent. $22.4 \%$ were of good quality, $24.5 \%$ were average, $37.2 \%$ of limited quality and $8.5 \%$ of the videos were of bad quality. In JAMA scoring, it was observed that $16.0 \%$ were completely sufficient, $61.7 \%$ were partially sufficient, and $22.3 \%$ of the videos were insufficient. In the usefulness scoring system, $15.9 \%$ were categorized as very useful, $41.5 \%$ were categorized as useful and $42.6 \%$ of the videos were categorized as not useful. Finally, $18.1 \%$ were good, $55.3 \%$ were moderate and $26.6 \%$ of the videos were insufficient in the DDS system. 
The contents of the videos were as follows: $45.7 \%$ nutrition education, $43.6 \%$ informative, $6.4 \%$ advertisements, and $4.3 \%$ patient experience. When the sources of the videos were examined, $41.5 \%$ were physician-sourced, $25.5 \%$ dietitiansourced, $19.2 \%$ commercial-sourced, and $13.8 \%$ patient-sourced.
Comparisons between the scores within the scope of this study and the video sources are given in Table 3. Physician, dietitian, commercial, and patient-sourced videos differed significantly in DISCERN, GQS, and usefulness scores $(\mathrm{p}<0.05)$. Before group comparison, Bonferroni Correction was done.

Table 2. The descriptive statistics $(n=94)$

\begin{tabular}{llllll}
\hline & & Standard & & \\
& Mean & Deviation & Minimum & Maximum & Median \\
\hline DISCERN & 35.41 & 13.99 & 16.00 & 76.00 & 30.50 \\
GQS & 2.83 & 1.10 & 1.00 & 5.00 & 3.00 \\
JAMA & 2.54 & 1.01 & 1.00 & 4.00 & 3.00 \\
Usefulness & 3.80 & 2.53 & 1.00 & 10.00 & 3.00 \\
DDS & 4.94 & 2.05 & 1.00 & 10.00 & 5.00 \\
Time since upload (days) & 1447.74 & 1011.42 & 84.00 & 4025.00 & 1316.00 \\
Run time (min) & 13.10 & 19.90 & 0.55 & 87.28 & 4.54 \\
Views & 255111.68 & 880401.40 & 4.00 & 6229683.00 & 12723.50 \\
Likes & 2920.82 & 11585.92 & 0.00 & 90000.00 & 120.00 \\
Dislikes & 225.22 & 892.11 & 0.00 & 7100.00 & 8.50 \\
Comments & 301.72 & 1465.15 & 0.00 & 13133.00 \\
View ratio & 185.56 & 577.53 & 0.00 & 3441.86 \\
Like ratio & 1791.48 & 16493.43 & 0.00 & 160000.00 \\
VPI & 1323.72 & 11171.51 & 0.00 & 108358.83 \\
\hline
\end{tabular}

JAMA: the Journal of the American Medical Association Score GQS: the Global Quality Score
DDS: Diabetic Diet Score

VPI: Video power index

Table 3. The comparison of the video sources and scores

\begin{tabular}{|c|c|c|c|c|c|}
\hline Variable & Physician $(n=39)$ & Dietitian $(n=24)$ & $\begin{array}{c}\text { Commercial } \\
(n=18)\end{array}$ & Patient $(n=13)$ & $\mathrm{p}$ \\
\hline DISCERN & $37(16-76)$ & $34(22-55)$ & $24(16-46)$ & $29(21-54)$ & 0.006* \\
\hline JAMA & $3(1-4)$ & $3(1-4)$ & $2(1-4)$ & $3(1-3)$ & 0.108 \\
\hline GQS & $3(1-5)$ & $3(1-5)$ & $2(1-4)$ & $3(2-4)$ & $0.02 *$ \\
\hline Usefulness & $4(1-10)$ & $3(1-8)$ & $2(1-6)$ & $3(1-7)$ & $0.018 *$ \\
\hline DDS & $5(1-10)$ & $5.5(3-10)$ & $4.5(2-7)$ & $4(1-8)$ & 0.093 \\
\hline VPI & $\begin{array}{c}11.2 \\
(0-2888.53)\end{array}$ & $\begin{array}{c}2.46 \\
(0.13-108358.83)\end{array}$ & $\begin{array}{c}21.93 \\
(0.40-3292.89)\end{array}$ & $\begin{array}{c}13.67 \\
(1.46-1802.51)\end{array}$ & 0.12 \\
\hline View ratio & $\begin{array}{c}12.61 \\
(0-3116.40) \\
\end{array}$ & $\begin{array}{c}2.46 \\
(0.13-836.16)\end{array}$ & $\begin{array}{c}23 \\
(0.45-3441.86) \\
\end{array}$ & $\begin{array}{c}14.11 \\
(1.78-2117.95) \\
\end{array}$ & 0.085 \\
\hline
\end{tabular}

Kruskal-Wallis test results were given with the median (minimum-maximum) values.

JAMA: the Journal of the American Medical Association Score

GQS: the Global Quality Score

DDS: Diabetic Diet Score

VPI: Video power index

The video power index (VPI) and view rate were used to determine the popularity of a video. The VPI was calculated using the equation [like ratio $\times$ view ratio/100], as described by Erdem et al., the like ratio was calculated using the equation (like $\times 100 /[$ like + dislike]), and the view ratio was calculated using the equation [number of views/time since upload] (Erdem et al. 2018; Celik et al. 2020).

Since there were four groups in the study, the significance level was accepted as $.05 / 4=.0125$. There was no significant difference between the groups in terms of JAMA or DDS scores, VPI, or view ratio $(\mathrm{p}>0.05)$. In the DISCERN, GQS, and usefulness scores, physician sourced videos had statistically higher scores than commercial-sourced videos $(p<0.05)$. On the other hand, JAMA, DDS, VPI, and view ratio scores did not differ in terms of the video source $(p>0.05)$. 
Table 4. Correlations between variables

\begin{tabular}{|c|c|c|c|c|c|c|}
\hline Variables & $\begin{array}{c}\text { VPI } \\
(\text { rho; p) }\end{array}$ & $\begin{array}{c}\text { DISCERN (rho; } \\
\text { p) }\end{array}$ & $\begin{array}{l}\text { JAMA (rho; } \\
\text { p) }\end{array}$ & $\begin{array}{l}\text { GQS (rho; } \\
\text { p) }\end{array}$ & $\begin{array}{l}\text { Usefulness (rho; } \\
\text { p) }\end{array}$ & $\begin{array}{c}\text { DDS } \\
(\mathrm{rho} ; \mathrm{p})\end{array}$ \\
\hline \multirow{2}{*}{ View ratio } & $.994 * *$ & -.139 & -.060 & -.045 & -.102 & -.048 \\
\hline & .000 & .181 & .567 & .664 & .330 & .643 \\
\hline \multirow{2}{*}{ Duration } & 0.152 & $.554 * *$ & $.518 * *$ & $.567 * *$ & $.433 * *$ & $.564 * *$ \\
\hline & .144 & .000 & .000 & .000 & .000 & .000 \\
\hline \multirow{2}{*}{ Likes } & $.918 * *$ & -.041 & .026 & .019 & -.036 & .026 \\
\hline & .000 & .698 & .801 & .859 & .730 & .801 \\
\hline \multirow{2}{*}{ VPI } & & -.133 & -.058 & -.043 & -.092 & -.039 \\
\hline & & .202 & .581 & .680 & .377 & .712 \\
\hline
\end{tabular}

**Correlation is significant at the 0.01 level.

The video power index (VPI) and view rate were used to determine the popularity of a video. The VPI was calculated using the equation [like ratio $\times$ view ratio/100], as described by Erdem et al., the like ratio was calculated using the equation (like $\times 100 /[$ like + dislike]), and the view ratio was calculated using the equation [number of views/time since upload] (Erdem et al. 2018; Celik et al. 2020).

Table 4 contains correlation analysis results between the video features and the scoring systems. There was a significant and positive correlation between the view ratio and VPI. As the view ratio increased, the VPI also increased $(p<001)$. There were no significant correlations between the view ratio and DISCERN, JAMA, GQS, usefulness, or DDS scores ( $p>0.05)$. While there was a statistically significant and positive relationship between DISCERN, JAMA score, GQS, usefulness score, DDS, and duration $(p<0.01)$, the correlations with the VPI were insignificant $(p>0.05)$. There was a significant correlation between the number of likes and VPI. The VPI increased with the number of likes $(p<0.01)$. The relationship of the number of likes with other variables was found to be insignificant $(p>0.05)$. It was concluded that there was no significant relationship between the VPI and DISCERN, JAMA, GQS, usefulness, or DDS scores ( $\mathrm{p}>0.05)$.

In recent years, there has been a significant increase in the number of patients receiving counseling over the internet. YouTube is an online platform that provides easy access to relevant informational content (Desai et al. 2013). The present study aimed to evaluate the accuracy, and the quality of the information of the videos about diabetes and nutrition on YouTube. YouTube, one of the most popular video sharing platforms today, is used increasingly every day to spread healthrelated information. Although videos on diabetes have educational characteristics for the treatment and prevention of the disease, the insufficiency and poor quality of the available information should also be taken into account. For this reason, web-based information sources cannot replace the professional physician-patient relationship (Pons-Fuster et al. 2020). Additionally, it may become more difficult to inform patients correctly after they have received false information on the internet. In a study of Madathil et al. conducted on health data on YouTube, it was concluded that because YouTube is one of the most accessed websites worldwide, misleading information about healthcare is very likely to spread to patients easily. It was argued that the patients' ease of access to this misleading information may have negative consequences (Madathil et al. 2015).

In the present study, $4.3 \%$ of the videos concerned patient experience, $43.6 \%$ were informative, $45.7 \%$ concerned nutrition education, and $6.4 \%$ were advertisements. The average scores of the DISCERN, GQS, JAMA, usefulness and DDS systems were 35.41 (out of 92), 2.83 (out of 6), 2.54 (out of 5), 3.80 (out of 11), and 4.94 (out of 11), respectively. The view ratio of videos can be used as an alternative way to determine availability. The content e-ISSN: 2148-2683 of this study includes commercial and patient-sourced videos, videos with higher VPI scores, and view ratios. The VPI rates of physician-, dietitian-, commercial- and patient-sourced videos were 11.2, 2.46, 21.93, and 13.67, respectively. The VPI showed a significant positive correlation with view ratio, duration, and the number of likes $(p<0.001)$. According to the results, Physician, dietitian, commercial, and patient-sourced videos differed significantly in DISCERN, GQS, and usefulness scores $(\mathrm{p}<0.05)$. In the DISCERN, GQS, and usefulness scores, physician sourced videos had statistically higher scores than commercial-sourced videos (.0125). Additionally, the accessibility of physician-, dietitian-, and commercial-sourced videos in DDS scoring was found to be significantly higher than that of patient-sourced videos $(p<0.001)$. In the DISCERN scoring, $36.2 \%$ of the videos were poor and $29.8 \%$ were very poor. For this reason, it is suggested that YouTube users may often obtain insufficient information. The DISCERN scoring was developed in a study conducted by Lee for gallbladder diseases (Lee et al. 2014). In 2018, Erdem and Şişik edited Lee's scoring to make it more suitable for the bariatric surgery group and used it in their studies (Erdem \& Sisik, 2018). The DISCERN and GQS scores were accepted and used as a reference in a study on YouTube information on diabetes and oral health by Pons-Fuster et al. in which ninety-seven videos and YouTube videos about diabetes and oral health were evaluated. As a result, it was found that $30.9 \%$ of the videos were useful, $62.9 \%$ contained misleading information, and $6.2 \%$ described patient experiences. In the study, it was determined that the gqs scores of the videos containing patient experience were low (Pons-Fuster et al. 2020). In another study that tested the usefulness of YouTube videos for diabetes, the usefulness rate of 2084 videos were below $50 \%$, and the rate of misleading information was found to be approximately $25 \%$ (Gimenez-Perez et al. 2020).

In this study, a positive correlation was observed when the video duration, VPI, and quality scores were compared. The findings are also in accordance with Biggs et al.'s study, which found that long videos have less visibility, and people tend to learn more from short videos (Biggs et al. 2013).

\section{Conclusion}

The quality of online information on diabetic nutrition provided by YouTube is generally poor. YouTube users generally preferred to watch patient-based and commercial videos that were of lower quality. 


\section{Acknowledgement}

The authors would like to extend their sincere thanks to anyone who contributed to this study.

\section{Conflict of interest}

The authors declare that they have no conflicts of interest.

\section{References}

Abedin, T., Ahmed, S., Al Mamun, M., Ahmed, S. W., Newaz, S., Rumana, N., \& Turin, T. C. (2015). YouTube as a source of useful information on diabetes foot care. Diabetes research and clinical practice, 110(1), e1-e4. https://doi.org/10.1016/j.diabres.2015.08.003

Atkinson, N. L., Saperstein, S. L., \& Pleis, J. (2009). Using the internet for health-related activities: findings from a national probability sample. Journal of medical Internet research, 11(1), e4. https://doi.org/10.2196/jmir.103

Bernard, A., Langille, M., Hughes, S., Rose, C., Leddin, D., \& Veldhuyzen van Zanten, S. (2007). A systematic review of patient inflammatory bowel disease information resources on the World Wide Web. The American journal of gastroenterology, 102(9), https://doi.org/10.1111/j.1572-0241.2007.01325.x

Biggs, T., Bird, J., Harries, P., \& Salib, R. (2013). YouTube as a source of information on rhinosinusitis: the good, the bad and the ugly. The Journal of Laryngology \& Otology, 127, 749 754.

Celik, H., Polat, O., Ozcan, C., Camur, S., Kilinc, B. E., \& Uzun, M. (2020). Assessment of the Quality and Reliability of the Information on Rotator Cuff Repair on YouTube. Orthopaedics \& traumatology, surgery \& research: $\quad$ OTSR, 106(1), 31-34. https://doi.org/10.1016/j.otsr.2019.10.004

Charnock, D., Shepperd, S., Needham, G., \& Gann, R. (1999). DISCERN: an instrument for judging the quality of written consumer health information on treatment choices. Journal of epidemiology and community health, 53(2), 105-111. https://doi.org/10.1136/jech.53.2.105

COŞANSU G (2015). Diyabet: Küresel Bir Salgın Hastalık. Okmeydanı Tıp Dergisi, 31(ek sayı), 1 - 6.

Desai, T., Shariff, A., Dhingra, V., Minhas, D., Eure, M., \& Kats, M. (2013). Is content really king? An objective analysis of the public's response to medical videos on YouTube. PloS one, $8(12)$,

e82469.

https://doi.org/10.1371/journal.pone.0082469

Diabetes Canada Clinical Practice Guidelines Expert Committee, Sievenpiper, J. L., Chan, C. B., Dworatzek, P. D., Freeze, C., $\&$ Williams, S. L. (2018). Nutrition Therapy. Canadian journal of diabetes, 42 Suppl 1, S64-S79. https://doi.org/10.1016/j.jcjd.2017.10.009

Erdem, H., \& Sisik, A. (2018). The Reliability of Bariatric Surgery Videos in YouTube Platform. Obesity surgery, 28(3), 712-716. https://doi.org/10.1007/s11695-017-2911-3

Erdem, M. N., \& Karaca, S. (2018). Evaluating the Accuracy and Quality of the Information in Kyphosis Videos Shared on YouTube. Spine, 43(22), E1334-E1339. https://doi.org/10.1097/BRS.0000000000002691

Esen, E., Aslan, M., Sonbahar, B. Ç., \& Kerimoğlu, R. S. (2019). YouTube English videos as a source of information on breast self-examination. Breast cancer research and treatment, 173(3), 629-635. https://doi.org/10.1007/s10549018-5044-Z

Ferhatoglu, M. F., Kartal, A., Ekici, U., \& Gurkan, A. (2019). Evaluation of the Reliability, Utility, and Quality of the Information in Sleeve Gastrectomy Videos Shared on Open Access Video Sharing Platform YouTube. Obesity surgery, 29(5), 1477-1484. https://doi.org/10.1007/s11695019-03738-2

Fox, S., \& Duggan, M. (2013). Tracking for health. Pew Research Center's Internet \& American Life Project.

Gimenez-Perez, G., Robert-Vila, N., Tomé-Guerreiro, M., Castells, I., \& Mauricio, D. (2020). Are YouTube videos useful for patient self-education in type 2 diabetes? Health informatics journal, 26(1), 45-55. https://doi.org/10.1177/1460458218813632

Han, T., Gao, J., Wang, L., Li, C., Qi, L., Sun, C., \& Li, Y. (2020). The Association of Energy and Macronutrient Intake at Dinner Versus Breakfast with Disease-Specific and All-Cause Mortality Among People With Diabetes: The U.S. National Health and Nutrition Examination Survey, 20032014. Diabetes care, 43(7), 1442-1448. https://doi.org/10.2337/dc19-2289

Kocyigit, B. F., \& Akaltun, M. S. (2019). Does YouTube provide high quality information? Assessment of secukinumab videos. Rheumatology international,39(7), 1263-1268. https://doi.org/10.1007/s00296-019-04322-8

Landis, J. R., \& Koch, G. G. (1977). The measurement of observer agreement for categorical data. Biometrics, 33(1), 159-174.

Lee, J. S., Seo, H. S., \& Hong, T. H. (2014). YouTube as a source of patient information on gallstone disease. World journal of gastroenterology, 20(14),

4066-4070. https://doi.org/10.3748/wjg.v20.i14.4066

Madathil, K. C., Rivera-Rodriguez, A. J., Greenstein, J. S., \& Gramopadhye, A. K. (2015). Healthcare information on YouTube: A systematic review. Health informatics journal, 21(3), https://doi.org/10.1177/1460458213512220

Nason, G. J., Kelly, P., Kelly, M. E., Burke, M. J., Aslam, A., Giri, S. K., \& Flood, H. D. (2015). YouTube as an educational tool regarding male urethral catheterization. Scandinavian journal of urology, 49(2), 189-192. https://doi.org/10.3109/21681805.2014.975837

Özer, E. (2019). Diyabette Trbbi Beslenme Tedavisinin Uygulanması ve Diyetisyenin Sorumlulukları. Bes Diy Derg 2019;47(Özel Sayl):5-14.

Pant, S., Deshmukh, A., Murugiah, K., Kumar, G., Sachdeva, R., \& Mehta, J. L. (2012). Assessing the credibility of the "YouTube approach" to health information on acute myocardial infarction. Clinical cardiology, 35(5), 281-285. https://doi.org/10.1002/clc.21981

Pons-Fuster, E., Ruiz Roca, J., Tvarijonaviciute, A., \& LópezJornet, P. (2020). YouTube information about diabetes and oral healthcare. Odontology, 108(1), 84-90. https://doi.org/10.1007/s10266-019-00445-3

Rittberg, R., Dissanayake, T., \& Katz, S. J. (2016). A qualitative analysis of methotrexate self-injection education videos on YouTube. Clinical rheumatology,35(5), 1329-1333. https://doi.org/10.1007/s10067-015-2910-5

Rutten, L. J., Squiers, L., \& Hesse, B. (2006). Cancer-related information seeking hints from the 2003 Health Information National Trends Survey (HINTS). Journal of health 
communication, $11 \quad$ Suppl 1, 147-156. https://doi.org/10.1080/10810730600637574

Silberg, W. M., Lundberg, G. D., \& Musacchio, R. A. (1997). Assessing, controlling, and assuring the quality of medical information on the Internet: Caveant lector et viewor--Let the reader and viewer beware. JAMA, 277(15), 1244-1245.

Smith, P. E., McGuire, J., Falci, M., Poudel, D. R., Kaufman, R., Patterson, M. A., Pelleschi, B., \& Shin, E. (2019). Analysis of YouTube as a Source of Information for Diabetic Foot Care. Journal of the American Podiatric Medical Association, 109(2), 122-126. https://doi.org/10.7547/16149

Tolu, S., Yurdakul, O. V., Basaran, B., \& Rezvani, A. (2018). English-language videos on YouTube as a source of information on self-administer subcutaneous anti-tumour necrosis factor agent injections. Rheumatology international, 38(7), 1285-1292. https://doi.org/10.1007/s00296-018-4047-8

Wild, S., Roglic, G., Green, A., Sicree, R., \& King, H. (2004). Global prevalence of diabetes estimates for the year 2000 and projections for 2030. Diabetes care, 27(5), 1047-1053. https://doi.org/10.2337/diacare.27.5.1047 